\title{
EAP and LLNP Students: Common Problems and Strategies
}

\author{
NGUYEN, Thi Minh Phuong \\ University of New South Wales, 8/51 Forsyth St, Kingsford, NSW 2032 \\ E-mail: phuongbridim@yahoo.com
}

\begin{abstract}
As English learners originate from many cultural and language backgrounds, they come to class with different circumstances. This paper examines the backgrounds, common problems and solutions for English for Academic Purposes (EAP) students and Language, Literacy, and Numeracy Programme (LLNP) students. EAP students are from Meridian International School based in Surry Hills, Sydney, and LLNP students are from MTC Training Solutions, an LLNP provider commissioned from the Australian government to offer students with English language and numeracy proficiency to gain sustainable employment in Australia. This paper will introduce and provide insights into EAP and LLNP programmes from the perspective of a teacher/trainer. It will highlight the differences in the backgrounds of the two programmes and identify their problems and solutions, thus maximise students' learning outcomes.
\end{abstract}

Keywords: Academic English, LLNP, Problems, Teaching strategies

\section{English for Academic Purposes (EAP)}

\section{I.1. Background of EAP}

It is interesting to know that the first recorded use of English for Academic Purposes originates from England. Johns (1981) used that term in a conversation with two British Council officers in October 1974. By 1975, it was in more general use. English for Academic Purposes (EAP) is a multi-faceted area within the wider field of English language teaching (ELT), and is one of the most common forms of English for Specific Purposes (ESP) (Benesch, 2001; Jordan, 1997). According to Gillett and Wray (2006), EAP is a practical branch of ELT in which the role of the EAP teacher is to locate what the students need in their academic courses, and assist them to perform better in a specific time-frame. It aims to teach students vocabulary, grammar, pronunciation and the four macro-skills which prepare students for tertiary or vocational education. In addition, EAP practitioners often find that, either directly or indirectly, they are teaching study skills (Graham, 1997). Those skills taught in EAP courses are:

- $\quad$ essay writing,

- $\quad$ report writing,

- $\quad$ research skills,

- $\quad$ critical thinking,

- $\quad$ effective listening and note-taking skills,

- $\quad$ oral presentation skills,

- $\quad$ and active participation skills in group and classroom discussions.

EAP also aims to resolve differences in academic life wherein students might experience some course of actions that might often be considered acceptable in their culture, but not in the new learning environment. For example, plagiarism is deemed appropriate in certain countries, whereas in English-speaking countries like Australia or England, it is an academic misconduct. The increase of overseas students in Western nations leads to the on-going preparation in terms of language and academic life for these groups of students so that they can be well-informed and well-equipped in the new learning spectrum. Ultimately, EAP course aims to prepare students in terms of English language proficiency. In Australia, or the UK, this means assisting students to reach a score of 6 or above in the IELTS (International English Language Testing System). In the US, this means helping students attain a score of 500 or greater in the TOEFL (Test of English as a Foreign Language). Numerous efforts were put into academic writing, as in most English-medium institutions, this is where students are frequently required to present their ideas. At undergraduate level, writing activities can range from a laboratory report to an extended essay of 10,000 words. Postgraduates are even requested to write 25,000 words for academic assignments or theses. In order to produce an adequate piece of writing in academic standards, students are to be well-equipped with the notion of genre in writing. Genre represents how writers typically use languages to respond to specific tasks in given situations. It is commonly accepted that texts are most successful when they 
employ conventions that other members of the academic community find familiar and convincing. It is also worth mentioning that as different disciplines require particular genres of writing in terms of references, assessments, quotations, etc., a range of needs analysis needs to be conducted among students to ensure that the quality of their future assignments are met in terms of academic writing standards.

EAP is an educational approach in ELT with a totally different approach from General English courses (Candlin \& Mercer, 2001). EAP focuses on reading and writing, whereas many General English concentrates on speaking and listening (Knapp \& Seidlhofer, 2009). EAP courses tend to teach formal, academic genres rather than conversational and social genres in General English courses. In most universities in Australia, EAP is the pre-sessional pathway where learning skills are provided to students to engage them into academic environment.

\section{I.2. Common problems of EAP students}

EAP students in this paper are from Meridian International School based in Surry Hills, Sydney. The students come from a variety of countries such as China, India, Vietnam and other Asian nations. Most students have achieved pre-intermediate level of English, or IELTS of 5 or 5.5. They need to enhance their four macro-skills in English to ensure that they are well-prepared for tertiary education or vocational training. Their speaking and listening skills are of acceptable level because of the immersion of media exposure in English in these developing countries. They have been taught conversational English in the early years of their lives. Most students are familiar with slangs that they watch on American movies. The biggest obstacle that these students encounter is their writing skills. The grammatically correct and structured sentences are what these students aim for. EAP course is designed to help students achieve that goal. Enhancing writing skills together with mastering reference styles (APA, Harvard, or Chicago Manual of Style), understanding these styles and making sense of how the system works are essential features of an EAP course. With regard to reading skills, students are instructed on how to obtain information quickly from textbooks and other reading materials to fulfil the requirements of the course. Skimming and scanning are two important skills for students. Before the lecture begins, students are required to read hundreds of pages on technical issues, thus the ability to select and remember necessary information are essential for the survival and thriving of these students. Furthermore, students are also provided with other academic learning skills such as presentation skills, essay writing skills, communication skills and note-taking skills.

\section{I.3. Strategies for EAP students}

In order to assist students reach the best learning outcomes, teachers/trainers should provide students with clear outcomes and expectations with levels of expected competences (Carter \& Nunan, 2001; Danielson, 2007). Teachers need to design the syllabus according to the expectations of the students. Teachers should also continuously raise students' awareness of what are required from students. As most overseas students are from Asian countries, collaborative learning styles are prevalent in classroom environment (Salili \& Hoosain, 2007). In English language classroom, interaction between student/student and between student/teacher plays a crucial role in developing students' learning outcomes, especially in the area of listening and speaking skills (Candlin \& Mercer, 2001).

With regard to writing in academic English, it would be very productive if students are taught the academic genre before they actually write the paper. Unless students fully understand an academic article, they will not be able to produce a similar genre. What is more, if students are not taught the vocabulary associated with academic writing, they will find it difficult to understand the meanings and collocations of sophisticated words. Writing is an integral and important part of EAP courses (Blue, 2000; Hinkel, 2004). EAP students are normally required to write a long essay about a topic of their choice. This assignment is to be conducted over the period of 7-8 weeks. The topic is to be distributed to students at week 2 of the 10-week course. Students are asked to collect information and develop their ideas to compose an essay. Teachers play a significant role in assisting students build up the essay. During this time, feedback from teachers is exclusively essential. Feedback should come at the drafting stage, giving students chances to incorporate teachers' comments into subsequent drafts. It should be provided in the form of one-on-one discussion where questions are raised and students have chances to communicate their ideas. At this stage, students can clarify their thoughts and make the best choice of words by exchanging their thoughts with their teachers. On the basis of what the teacher suggests, students have opportunities to improve their writing skills, and avoid mistakes in their future assignments. Students then develop on the smooth flow and transitions between passages. In that approach, they feel more confident and more prepared for their academic life. Additions and suggestions about text organisation can be utilised to help students express themselves in a comprehensible approach. 
It would be highly recommended that students are given chances to make presentations in front of their classmates. Students from Asian countries, especially South East Asian countries like China, Thailand, Japan, Korea, and Vietnam are from teacher-centred learning environments, where teachers have unquestioningly upmost authority. Students are not allowed to ask questions or raise their voices in classroom (Hollins, 1996; Oxford, 1996). Students from these countries are very reserved and do not want to express their ideas freely. This circumstance makes it difficult for students to integrate themselves in a Western style classroom where they are required to present their ideas, to refute others' opinions, and to assert themselves in academic environments in an intellectual manner. Raising students' self-esteem, confidence and assertiveness is of significant values to the success of the programme.

All in all, students' writing skills, reference skills, and presentation skills are the three areas that need to be improved in an EAP course. As the learning needs and the psychological features of this group of students are distinctly different from other groups, it is teachers' responsibility to ensure that learners are well-prepared for their tertiary or vocational education in terms of academic English performance.

\section{Language, Literacy and Numeracy Programme (LLNP)}

\section{II.1. Background of LLNP}

Literacy and Numeracy are of significant values in our lives. They are directly or indirectly linked to the physical, social and economic security of individuals, and ultimately to a country's well-being. Raising students' literacy and numeracy skills help to ensure that students are well-prepared for their study and their career. The LLNP (Language, Literacy and Numeracy Programme) provides basic Language, Literacy and Numeracy training for eligible job-seekers. The programme aims to enhance clients' language, literacy and/or numeracy with the expectation that such improvements will enable them to participate more effectively in training or in the labour force, gain sustainable employment and lead to greater benefits for society in the long term. The LLNP is funded by the Australian government and is designed to meet the needs of students, to satisfy the demands of industries and local businesses, and to provide practical skills to students in job applications. This programme is funded by the Department of Education, Science and Training for migrants who have registered with Centrelink (an organisation that delivers services to assist people to become self-sufficient and supporting those in need) as job-seekers. Before students enrol in a specific class, their English language skills are assessed by an in-house assessor trained to provide students with a test in 4 macro-skills (listening, speaking, reading, and writing). An individual training plan for students will be drawn within a reasonable timeframe after the assessment phase. Both the teacher and students are expected to closely follow the training plan. Students are not allowed to be absent from classroom for more than 20 per cent of the required attendance duration. Otherwise, they will be suspended from the training.

One of the training providers commissioned by the Australian government to conduct LLNP programmes for students is MTC Training Solutions. The Certificates I-IV in Spoken and Written English are considered to be the foundation of the entire training curriculum, with the aim to provide teachers a framework on what needs to be fulfilled at the end of each 200-hour block of training.

\section{II.2. Common problems of LLNP students}

Those participants in this class are mostly adult learners, who come to Australia as migrants and have nearly no prior English language. Some students are even illiterate in their own native language. There are five groups of learners:

- learners who possess no literacy skills in their home countries;

- learners who were Australian-born but dropped out of schooling very early in their life, so their literacy and numeracy skills are very low;

- learners who prefer grammatical practice to speaking or vice versa;

- learners with pictographic writing systems (Chinese, Thai, Korean) where they have to study how to write the alphabet as the first step;

- and learners with very diverse motivations and socio-linguistic and cultural backgrounds.

Adult learners have limited motivation to learn than other age groups. They have family commitments and related issues to deal with during their daily lives. Some students come to class not to earn knowledge, but to satisfy Centrelink welfare requirements. If a student's attendance is below the requirements, Centrelink will cut their welfare payments. Thus the internal motivation of these students does not exist. It is the teacher/trainer's responsibility to enhance students' motivation by organising extra-curricular activities to increase their 
enthusiasm to attend classes. Another problem is that as students are mature learners, they are very sensitive in their classroom behaviours. Teachers/trainers need to be understanding and know how to treat students with respect.

\section{II.3.Strategies for LLNP students}

There are several approaches to teaching LLNP learners. First of all, students can use their skills to help each other in a friendly learning environment. Peer-learning has proved itself to be an effective classroom interaction (Milson, 1973; Topping \& Ehly, 1998). Those students assisted by their friends/classmates will not feel intimidated as when they are approached by their teachers/trainers. As the student intake is conducted on a weekly basis, students in the same class have different learning paces and progresses. Teachers can sometimes rely on more advanced students to support their classmates. In this way, teachers will save time and reduce their stress in the classroom. More often than not, classroom preparation is very time-consuming and the assistance from more advanced students will be of significant values. Moreover, peer learning can help students adopt the most effective learning strategies for themselves (O'Donnell \& King, 1999). It would be best if teachers can create a learning environment where students feel that they are playing and working, not studying, as most learners are adults. It will generate a lot of pressure if students feel they are under supervision like children. Group-work, under proper conditions, creates a friendly learning environment for students and their teachers (Brandler \& Roman, 1999; Cohen, 1994; Doel, 2006). Studying collaboratively has shown to directly enhance learning. Also, once students enter the workforce, their employers will highly value the co-operation of the students with fellow colleagues. In this collaborative learning environment, teachers should ensure that students feel welcomed and relaxed, so that students will increase their self-esteem and confidence level. In terms of course design and curriculum development, it is necessary to conduct a needs analysis. On that basis, the course designer can propose an appropriate syllabus and methodology that aims to develop students' skills (Yalden, 1997). Once the course has been conducted, it needs to be regularly updated with the evaluation in terms of its effectiveness.

As discussed, LLNP aims to provide learners with appropriate competence for everyday conversation to gain sustainable employment in Australian context. The programme has proved to be successful in recent years. To ensure a prolonged and continued success, teachers/trainers need to ascertain that students are highly externally motivated. This can be achieved by providing a stress-free learning environment where students are allowed to interact with their fellow classmates. Assignments specified for students should be based on daily activities such as shopping, going on holiday, finding ways around, rather than academic technicalities.

To sum up, whereas EAP aims to provide learners with Academic English, LLNP seeks to provide students with General English capabilities. Thus the applications and practice of the two programmes need to be adjusted so as to ensure the best possible learning outcomes for students. As with EAP students, writing and reading in academic contexts should be emphasised, while speaking and listening in real-life situations are to be the focal attention for LLNP learners. Teaching tips and techniques for those two categories of students are specifically mentioned within the article.

\section{References}

Benesch, S. (2001). Critical English for academic purposes: theory, politics, and practice. New Jersey: Routledge.

Blue, G. M. (2000). Assessing English for academic purposes. Oxford: Language Publishers.

Brandler, S., \& Roman, C. P. (1999). Group work: skills and strategies for effective interventions. New York: Routledge.

Candlin, C., \& Mercer, N. (2001). English language teaching in its social context: a reader. New York: Routledge.

Carter, R., \& Nunan, D. (2001). The Cambridge guide to teaching English to speakers of other languages. Cambridge: Cambridge University Press.

Cohen, E. G. (1994). Designing groupwork: Strategies for the heterogeneous classroom. New York: Teachers College Press.

Danielson, C. (2007). Enhancing professional practice: a framework for teaching. Alexandria, VA: Association for Supervision and Curriculum Development.

Doel, M. (2006). Using groupwork. New York: Routledge. 
Graham, S. (1997). Effective language learning: positive strategies for advanced level language learning. Vol. 6 of Modern languages in practice. New York: Multilingual Matters.

Hinkel, E. (2004). In teaching academic ESL writing: Practical techniques in vocabulary and grammar. New Jersey: Routledge.

Hollins, E. R. (1996). Culture in school learning: Revealing the deep meaning. New Jersey: Routledge.

Johns, T. F. (1981). Some problems of a world-wide profession. In J. McDonough, \& T. French (Eds.). The ESP teacher: role, development and prospects. ELT Documents: 112.

Jordan, R. R. (1997). English for academic purposes: a guide and resource book for teachers. Cambridge: Cambridge University Press.

Knapp, K., \& Seidlhofer, B. (2009). Handbook of foreign language communication and learning. Berlin: Walter de Gruyter.

Milson, F. (1973). An introduction to group work skill. London: Taylor \& Francis.

O'Donnell, A. M., \& King, A. (1999). Cognitive perspectives on peer learning. New Jersey: Routledge.

Oxford, R. L. (1996). Language learning strategies around the world. Honolulu National Foreign Language Resource Centre.

Salili, F., \& Hoosain, R. (2007). Culture, motivation, and learning: a multicultural perspective. Charlotte, NC Information Age Publishing.

Topping, K. J., \& Ehly, S. W. (1998). Peer-assisted learning. New Jersey: Routledge.

Yalden, J. (1997). Principles of course design for language teaching. Cambridge: Cambridge University Press. 